\title{
Architecture of high-strength aluminum-matrix composites processed by a novel microcasting technique
}

\author{
Chenwei Shao', Shuo Zhao ${ }^{2}$, Xuegang Wang ${ }^{1}$, Yankun Zhu', Zhefeng Zhang ${ }^{1}$ and Robert O. Ritchie ${ }^{3}$
}

\begin{abstract}
As important lightweight structural materials, cast aluminum alloys have been largely used in the transportation and aerospace industries. In general, Al-Si-based alloys comprise more than $90 \%$ of all castings due to their excellent castability and corrosion resistance. However, even though various reinforcements have been introduced, the strength of these alloys is not that high, which severely limits their use for certain high-performance applications. Here, we report on a new strategy and technology to reinforce Al-Si alloys to increase their yield strength into the $\sim 400-660 \mathrm{MPa}$ range, a level that is $29-113 \%$ higher than that of all current cast Al-Si alloys, laboratory or commercial, and comparable to that of many high-strength steels but with $\sim 40 \%$ lower density. By introducing continuous Ti-6Al-4V reinforcements into the Al-Si matrix through a novel microcasting process, the yield strength of the resulting alloy can be enhanced to between 4 and 6 times higher than that of the pure Al-Si alloy. The extraordinary reinforcing effect originates from the occurrence of multiscale strengthening mechanisms, including macroscale compound strengthening (the rule of mixtures amended by crack arrest mechanism), mesoscale straingradient strengthening, and microscale interface-affected-zone and nanoparticle strengthening. The core principle of our material design is to make all components of the composite fully participate in plastic (compatible) deformation, and thus, continuous reinforcements, instead of discrete reinforced structures (e.g., particles, whiskers, and short fibers), were introduced into the Al-Si alloy. Combined with 3-D printing technology, the present microcasting process can realize strengthening at the designed position by architecting specific reinforcements in the matrix.
\end{abstract}

\section{Introduction}

Aluminum-matrix composites (AMCs) are attractive and viable candidates for many military, aerospace, and automobile applications ${ }^{1}$ due to their light weight and high performance compared to that of many conventional casting metals and alloys. During the past decade, AMCs with different types of reinforcements, such as particles ${ }^{2}$,

\footnotetext{
Correspondence: Shuo Zhao (szhao14b@alum.imr.ac.cn) or

Zhefeng Zhang (zhfzhang@imr.ac.cn)

'Laboratory of Fatigue and Fracture for Materials, Institute of Metal Research,

Chinese Academy of Sciences, Shenyang 110016, P. R. China

${ }^{2}$ Key Laboratory of Fundamental Science for National Defense of Aeronautical

Digital Manufacturing Process, Shenyang Aerospace University, Shenyang

110136, P. R. China

Full list of author information is available at the end of the article.
}

whiskers ${ }^{3}$, fibers, ${ }^{4}$ and sheets ${ }^{5}$, have been produced to permit such composite alloys to be utilized in many practical applications ${ }^{1,6,7}$. Though many improvements have been made, the reality is that the degree of strengthening remains relatively low, especially when discontinuous reinforcements are employed. The basic reason for this situation lies in the fact that most reinforcements are much harder and stronger than the aluminum matrix so that strengthening is mainly accomplished by the reinforcement restricting the deformation of the aluminum matrix. In other words, the reinforcements themselves do not deform and thus only minimally participate in accommodating the external force with the matrix. However, when continuous fibers 
have been used to reinforce AMCs, invariably only one direction-the tension direction-is effectively reinforced, despite the high cost and complexities of fabricating these materials; accordingly, the use of these continuously reinforced AMCs has been limited and restricted to aerospace structures ${ }^{8}$. In light of these facts, alternative strengthening mechanisms would be desirable for AMCs to meet today's ever-increasing demand for higher strength low-density materials.

Significant developments have been achieved in recent years in processing metals with excellent mechanical properties by optimizing various combinations of different materials to achieve desired mechanical functionalities. Examples include functionally graded materials $(\mathrm{FGMs})^{9-11}$ and materials with periodic microstructures (e.g., multilayered or laminated materials) ${ }^{12,13}$. These heterogeneous high-performance materials show a common feature in their structure: they invariably contain continuous reinforcements, and generally two or more strengthening mechanisms are actively involved during deformation; these mechanisms can include strain partitioning $^{14}$, strain transformation ${ }^{12}$, interface constraint ${ }^{15}$, additional hardening ${ }^{16}$, back-stress strengthening ${ }^{17}$, etc. While these studies have substantially advanced the fundamental science of heterogeneous materials, it remains a major challenge to extend these materials and technologies to industrial applications due to the high cost, difficulties in processing and low production efficiency. As a typical continuous reinforced composite, rebar steelreinforced concrete is one of the most important structural materials in the building trade, not only because of its good performance but also due to its low manufacturing cost. Therefore, can high-strength AMCs also be architected like steel-reinforced concrete to effectively achieve superior and practical performance, for example, in aircraft integrated design (Fig. 1a)?

Inspired by the idea of introducing strong continuous reinforcements into a matrix to significantly enhance the strength, herein we report on a novel method, specifically the microcasting process, to reinforce a commercially cast aluminum alloy by introducing a titanium-alloy strut (i.e., frame structures consisting of small balls, columns, beams or sheets made by titanium alloy) in the material using a low-cost, high-efficiency process. Our present method makes it possible to architect an AMC "like building a house" through the ability to quantitatively reinforce the matrix with precise location and direction. Simultaneously, our approach permits the creation of multilevel strengthening mechanisms in the AMC, which further allows us to generate strength levels higher than those of almost all commercial casting aluminum alloys developed to date. Following the above guidelines, other casting techniques may be developed to produce metals with high mechanical performance.

\section{Materials and methods Material preparation}

A laboratory-made Chinese-designed casting aluminum alloy ZL114A and the commercial titanium alloy TC4 (Ti-6Al-4V) from Baoti group co. LTD in Baoji, China were chosen in this study. The $\mathrm{Al}$ alloy matrix used here is composed of (by weight) $6.91 \%$ silicon, $0.45 \%$ magnesium, and $0.11 \%$ titanium with a balance of aluminum; the $\mathrm{Ti}-6 \mathrm{Al}-4 \mathrm{~V}$ reinforcement comprises $6.28 \%$ aluminum and $4.11 \%$ vanadium with a balance of titanium. Compared to pure $\mathrm{Ti}, \mathrm{Ti}-6 \mathrm{Al}-4 \mathrm{~V}$ shows a much higher strength and toughness and is widely used as a structural material in many areas. The ball-reinforced AMC was fabricated by sprinkling $\mathrm{Ti}-6 \mathrm{Al}-4 \mathrm{~V}$ particles, which were prepared by gas atomization, into a molten $\mathrm{Al}$ alloy and holding the temperature at $800^{\circ} \mathrm{C}$ for $2 \mathrm{~h}$ in vacuo; the liquid alloy was subsequently poured into a square mold and finally air-cooled to room temperature. For the rodreinforced and plate-reinforced AMCs, Ti-6Al-4V wires and sheets were first cut from the block base metal (hotrolled commercial TC4) using a high-precision electric spark cutting machine (SKD3, Suzhou Sanguang Technology Co, Ltd.), and then, electrochemical polishing was performed to remove the oxide layer before the samples were regularly arranged and fixed on a holder. Next, the Ti wires and sheets were placed into the square molds together with the holder and then heated while the molten $\mathrm{Al}$ alloy was poured into the molds. The molten $\mathrm{Al}$ alloy with the Ti-6Al-4V frame was maintained at $800{ }^{\circ} \mathrm{C}$ for $2 \mathrm{~h}$ in a vacuum environment before being cooled to room temperature using an Ar flow. For AMCs with "brick wall" and lattice structures, Ti frames were created by Magics software (Materialise, Belgium) and printed by a BLT-S210 machine (Xi'an Bright Laser Technologies Co., Ltd.) through the selective laser melting (SLM) process and by an Arcam A1 machine through the electron beam melting (EBM) process ${ }^{18}$, respectively. It should be noted that all the $\mathrm{Ti}$ frames were wetted by fine $\mathrm{Al}$ powder at $800{ }^{\circ} \mathrm{C}$ in a vacuum environment before casting. This process is quite important and necessary to guarantee the flowability of liquid $\mathrm{Al}$ in or between $\mathrm{Ti}$ frames during casting and to ultimately influence the porosity of AMCs. A schematic representation of the microcasting process is summarized in Supplementary Fig. 1. Different from traditional casting technology, microcasting works using the liquid-solid adsorption principle and thus makes it possible to cast in a small (submillimeter-scale) space and fabricate components with complex structures.

\section{Compression, hardness tests, and DIC analysis}

The specimens used in the compression tests were $\sim 3 \times$ $3 \times 6 \mathrm{~mm}^{3}$ in size; they were spark-cut from the AMC ingots. Before compression testing, all specimens were electropolished in a solution of $\mathrm{HClO}_{4}: \mathrm{CH}_{3}\left(\mathrm{CH}_{2}\right)_{3} \mathrm{OH}$ : 


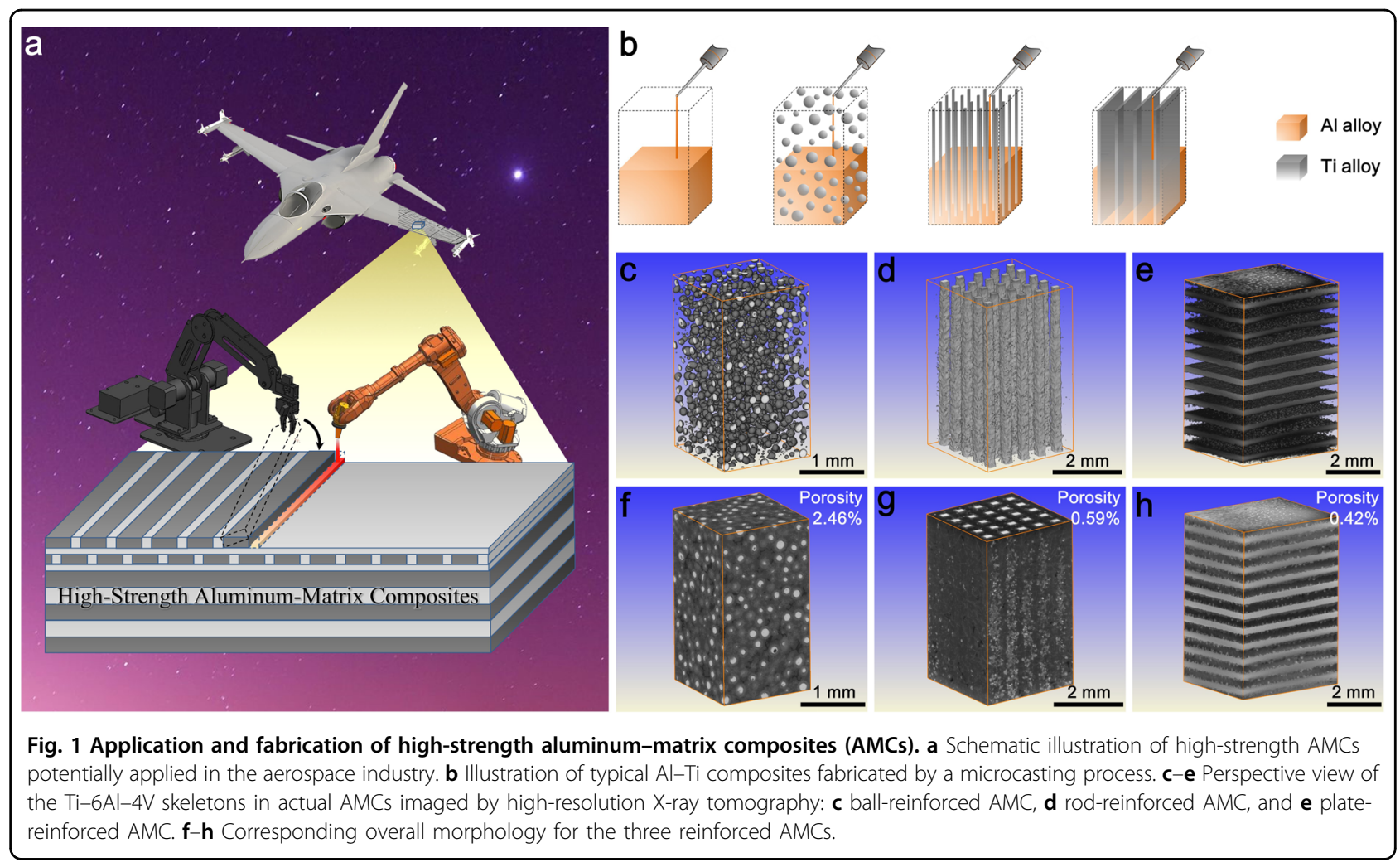

$\mathrm{CH}_{3} \mathrm{OH}=1: 6: 10$ (vol.) under a voltage of $20 \mathrm{~V}$ for $60 \mathrm{~s}$ at $-25{ }^{\circ} \mathrm{C}$ to produce a strain-free and smooth surface for microscopic observations. Uniaxial compressive tests were conducted at room temperature at a constant strain rate of $1 \times 10^{-3} \mathrm{~s}^{-1}$ using an Instron 8862 electrichydraulic testing machine equipped with a digital image correlation (DIC) component. Each test was repeated at least three times to ensure reliable results. Before performing the DIC imaging, a random pattern with appropriate scale and resolution is needed to cover the sample surface as strain markers. In this work, black paints were sprayed dispersedly on the whitened sample surface using a sprinkling can, forming a contrasting speckle pattern. The hardness was evaluated using an AMH43 fully automatic microhardness testing machine fitted with a Vickers indenter; a load of $100 \mathrm{~g}$ was applied with a holding time of $15 \mathrm{~s}$.

\section{High-resolution XRT analysis}

In situ high-resolution X-ray tomography (XRT) tests were performed using a Zeiss Versa XRM-500 system with an accelerating voltage of $120 \mathrm{kV}$ and power of $10 \mathrm{~W}$. The distribution and size of the defects, as well as the damage features, were identified and analyzed by $\mathrm{XRT}$ at an accelerating voltage of $100 \mathrm{kV}$ and voxel size of $6.82 \mu \mathrm{m}$. A total of 1600 projections were collected on a charge-coupled device detector using a $1 \mathrm{~s}$ exposure time.

\section{Laser marking and CLSM observation}

The plate-reinforced AMC sample was laser-marked with equidistant parallel lines on the surface before compression testing using a CNI EP-20 laser machine; this was used to assess the statistics of the local strain. Two- or three-dimensional surface damage morphologies of the compressed specimens were investigated by confocal laser scanning microscopy (CLSM) using an Olympus LEXT OLS400 microscope with a planar resolution of $120 \mathrm{~nm}$ and a height resolution of $10 \mathrm{~nm}$.

\section{SEM (including ECC, EDS, and EBSD) characterization}

A LEO Supra 35 field-emission SEM (operated at $20 \mathrm{kV}$ ) from Zeiss equipped with electron channeling contrast imaging (ECCI), energy dispersion spectroscopy (EDS) and electron backscatter diffraction (EBSD) components was employed to characterize the microstructure. The TSL-OIM analysis software was applied to perform the EBSD analysis to obtain information on the lattice distortion and grain rotation.

\section{TEM sample fabrication and TEM observations}

Samples prepared for TEM investigations were all spark-cut from the compression test specimens, before and after testing, from a section parallel to the loading direction, with an original thickness of $500 \mu \mathrm{m}$. The resulting thin plate was ground mechanically to $\sim 30 \mu \mathrm{m}$ in thickness and then further thinned by ion milling with 
a precision ion polishing system (Gatan 691) at $-100{ }^{\circ} \mathrm{C}$. TEM observation was carried out using an FEI Tecnai T12 TEM operated at a relatively low accelerating voltage of $120 \mathrm{kV}$ in an attempt to reduce the influence of the electron beam on the samples.

\section{Results}

\section{Structure and mechanical properties of AMCs with continuous reinforcement}

Three kinds of AMCs consisting of $\mathrm{Al}-\mathrm{Si}$ matrix and $\mathrm{Ti}-6 \mathrm{Al}-4 \mathrm{~V}$ reinforcements, as well as $\mathrm{Al}-\mathrm{Si}$ alloy without reinforcement, were fabricated by a microcasting process (Fig. 1b-h). The detailed processes in making such materials are given in the Methods section and in Supplementary Fig. 1. Reinforcements with three different shapes or macrodimensions, i.e., zero-dimensional (0-D) ball, 1-D rod, and 2-D sheet, were added into the matrix separately, as described below.

- Type 1-ball reinforcement: Ti-6Al-4V particles with diameters of $\sim 140-170 \mu \mathrm{m}$ were dispersed with an average spacing of $110 \mu \mathrm{m}$ in an aluminum matrix.

- Type 2-rod reinforcement: Ti-6Al-4V pillars, with cross-sectional dimensions of $180 \times 270 \mu \mathrm{m}^{2}$, were arranged periodically in the matrix with a spacing of $420 \mu \mathrm{m}$.

- Type 3-sheet reinforcement: Ti-6Al-4V plates, with a thickness of $300 \mu \mathrm{m}$, were layered alternately with matrix (thickness $450 \mu \mathrm{m}$ ).

All interfaces between the $\mathrm{Al} / \mathrm{Ti}$ phase were removed by the formation of the $\mathrm{Al}_{3} \mathrm{Ti}$ intermetallic phase (with an average thickness of $\sim 50 \mu \mathrm{m}$ for the present casting parameters), which is formed by the diffusion of titanium atoms from the reinforcement to the matrix when the temperature exceeds the melting point of aluminum ${ }^{19,20}$. Supplementary Fig. 2a-c present scanning electron microscopy (SEM) images showing the morphology and element distribution in the three AMCs. It should be noted that the large-scale $\mathrm{Al}_{3} \mathrm{Ti}$ coating precipitated on the $\mathrm{Ti}-6 \mathrm{Al}-4 \mathrm{~V}$ particles was designed with the purpose of not only "bridging" the matrix and reinforcements like glue but also connecting the $\mathrm{Ti}-6 \mathrm{Al}-4 \mathrm{~V}$ particles themselves together to form several larger reinforcements. That is, the Ti balls themselves in AMC constitute a quasi-continuous strut by connection with $\mathrm{Al}_{3} \mathrm{Ti}$. We find that both the $\mathrm{Al} / \mathrm{Al}_{3} \mathrm{Ti}$ and $\mathrm{Ti} / \mathrm{Al}_{3} \mathrm{Ti}$ interfaces were well connected, with no evidence of cracks found at the macro- and microscales (Supplementary Fig. 2a-e). Diffusion of $\mathrm{Si}$ atoms from $\mathrm{Al}_{3} \mathrm{Ti}$ to $\mathrm{Ti} / \mathrm{Al}_{3} \mathrm{Ti}$ interfaces was observed, however, as shown by the inset in Supplementary Fig. 2a; this was due to the low solubility of $\mathrm{Si}$ in intermetallic $\mathrm{Al}_{3} \mathrm{Ti}^{21,22}$, accompanied by the formation of nanosized silicides, especially near the $\mathrm{Al} / \mathrm{Al}_{3} \mathrm{Ti}$ and $\mathrm{Ti} /$ $\mathrm{Al}_{3} \mathrm{Ti}$ interfaces (Supplementary Fig. 2f). The $\mathrm{Al} / \mathrm{Al}_{3} \mathrm{Ti}$ interface is supposed to be a well-bonded but incoherent boundary, considering their $\left(\mathrm{Al}\right.$ and $\left.\mathrm{Al}_{3} \mathrm{Ti}\right)$ similar crystal structures $^{23}$ but no fixed relation on crystallographic orientation between the $\mathrm{Al}$ and $\mathrm{Al}_{3} \mathrm{Ti}$ on both sides of the interface (Supplementary Fig. 3). In contrast, the combination between the $\mathrm{Ti}$ and $\mathrm{Al}_{3} \mathrm{Ti}$ interface is much weaker, not only because of the large difference in crystal structure but also due to the concentration of $\mathrm{Si}$ at the interface. Thus, fine $\mathrm{Al}_{3} \mathrm{Ti}$ grains were usually found near the $\mathrm{Ti} / \mathrm{Al}_{3} \mathrm{Ti}$ interface (Supplementary Fig. 3j).

The compressive stress-strain behavior, shown in Fig. 2a, indicates that the strength of the $\mathrm{Al}$ matrix has been improved remarkably by the $\mathrm{Ti}$ alloy reinforcements. The hardenability, as quantified by the work-hardening rate, is
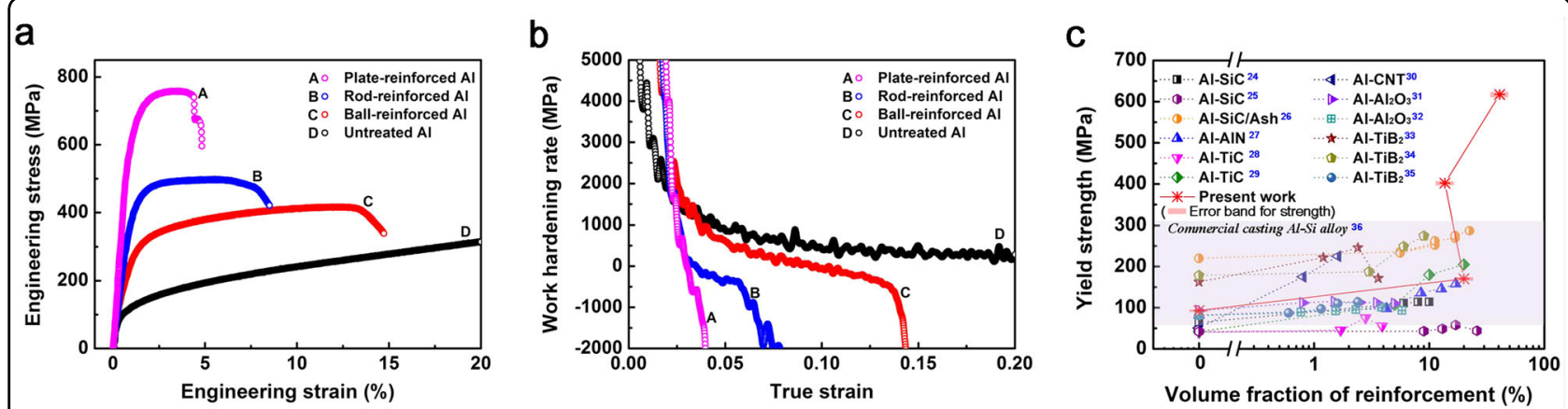

Fig. 2 Superior mechanical properties of AMCs. a Compressive engineering stress-strain curves for the different reinforcements. $\mathbf{b}$ Work hardening as a function of true strain upon compression of reinforced samples. $\mathbf{c}$ Comparison of yield strength as a function of the volume fraction of reinforcement for the present continuous (or semicontinuous) reinforced AMCs produced by microcasting and disperse reinforced cast AMCs fabricated by other methods, in addition to commercial casting aluminum alloys. Note that as the real-time strain in compression, measured in the stress-strain curves, was determined using digital image correlation (DIC) analysis of the average strain of the entire compression sample, the actual strain (deformation) may be larger than that measured after yielding, where the recognition rate of DIC decreases (see the corresponding references ${ }^{24,28,40-50}$ for further information). 
superior for all samples subjected to Ti reinforced at the early stage of deformation (true strain $<3.0 \%$ ), while it decreases rapidly until failure (Fig. 2b). Figure 2c compares the yield strength of many other cast AMCs strengthened by various reinforcements, which demonstrates that in general, continuous reinforcements can be optimized to produce superior matrix strengthening effects compared to those when using discrete reinforcements. According to the statistics quoted by Zolotorevsky et al. ${ }^{24}$, nearly all commercial and laboratory cast $\mathrm{Al}-\mathrm{Si}$ alloys display a $0.2 \%$ yield strength in the range from 55 to $310 \mathrm{MPa}$, with the highest strength of commercial alloys $(550 \mathrm{MPa})$ exhibited by the Ni-bearing $\mathrm{Al}-\mathrm{Zn}-\mathrm{Mg}$ highstrength alloy. Clearly, optimized additions of continuous reinforcements to an $\mathrm{Al}-\mathrm{Si}$ matrix would offer the potential to generate $\mathrm{Al}-\mathrm{Si}$ alloys, with their good casting performance, that possess the mechanical performance of high-strength aluminum alloys.

\section{Macrofailure and microdamage mechanisms}

To discern the specific effects of the three types of reinforcements on the mechanical behavior of AMCs, we need to investigate their macro/microstructure evolution and the salient deformation mechanisms underlying their properties. Figure $3 \mathrm{a}-\mathrm{c}$ presents image quality (IQ) maps obtained by in situ electron backscattered diffraction (EBSD), which show clear evidence of deformation in the $\mathrm{Al}$ matrix, indicated by its darkened area and distorted morphology, with minimal evidence of corresponding strain in the $\mathrm{Ti}-6 \mathrm{Al}-4 \mathrm{~V}$ particles. For an intuitive comparison, two regions (blue box and red point in Fig. 3a) in both the matrix and the reinforcement $(\alpha-\mathrm{Ti})$ were tracked to follow the crystal rotation during compression, caused mainly by slip inside the grain with compatible deformation restricted by neighboring grains. For the selected $\mathrm{Al}$ matrix with a facecentered cubic (fcc) structure, remarkable crystal rotation occurred that was associated with the rotation of the operating slip system during compression (Fig. 3d); the initial squeezing direction (black points) first activates the (111)[011] slip system and then gradually rotates towards the [1111] direction with further deformation. When the grain rotates to the direction between [101] and [001], another slip system (111)[101] also operates and forces the crystal to rotate towards [101] along the [101] to [001] direction as a result of double slip. For the selected regions (grains I and II in Fig. 3e), a multiple slip system was activated up to a total strain of $10 \%$, which corresponds to the results of Schmid factor analysis, i.e., both grains I and II show a double-slip orientation (Fig. 3f). In contrast, no obvious crystal rotation was found in the $\alpha$-Ti during compressive loading for strains up to $10 \%$ (Fig. $3 \mathrm{~d}$ ). The fact that deformation is principally concentrated in the matrix is further shown by the CLSM images in Fig. 3e and Supplementary Fig. 4, which indicate the condition of the surface following the copious slip in the matrix, compared to the markedly flat surface of the reinforcement. Microcracks located at Ti/ $\mathrm{Al}_{3} \mathrm{Ti}$ interfaces are generally found on the surface, with several extended into the Al matrix (Supplementary Fig. 4c). The macroscopic fracture process was recorded through in situ DIC technology (Fig. 3g) and indicates a shear-band-mediated fracture (i.e., the main fracture developed progressively by the initiation, deflection and connection of microcracks), commonly observed in highstrength materials ${ }^{25,26}$.

In situ high-resolution XRT technology was employed to investigate the deformation and fracture mechanisms of the rod-reinforced AMC (Fig. 4), with particular interest in the internal $\mathrm{Ti}-6 \mathrm{Al}-4 \mathrm{~V}$ strut. Initially, uniform elastic and plastic deformation can be seen to occur in both the matrix and reinforcement for strains up to $2 \%$ (comparing Fig. 4b, c). Once a strain of 5.2\% reached, the Ti alloy rods began to kink (Fig. 4d); with a further increase in strain to $7.2 \%$, local shearing may be observed in a few Ti-6Al-4V rods, accompanied by small cracks in the $\mathrm{Al}_{3} \mathrm{Ti}$ or at the $\mathrm{Ti} / \mathrm{Al}_{3} \mathrm{Ti}$ boundaries (Fig. 4e). During further compression, the neighboring rods also start shearing and cracking, forming a macroscale shear band by compatible deformation and finally leading to an overall failure (Fig. 4f). From a 3-D perspective, it can be learned that kinking and shearing may first occur in $\mathrm{Ti}$ rods in the strain-concentration zone and then develop to a macroscopic shear band along the weakest shearing plane at the latter plastic deformation stage (Fig. $4 \mathrm{~g}, \mathrm{~h}$ ). Compared to the reinforcement, the $\mathrm{Al}$ matrix exhibits an improved capacity for plastic deformation, with many fewer cracks forming in the interior or on the surface (Fig. 4f, i). That is, the $\mathrm{Al}$ matrix between Ti rods supports the loading and, more importantly, effectively retards microcrack coalescence by breaking cracks in neighboring Ti rods (Fig. 4e, f).

The CLSM images in Fig. 5 show the evolution of the surface morphology for the plate-reinforced AMC under compression; this surface was laser-marked prior to testing for the measurement of local strains. Macroscopically, no significant damage features were observed at the early stage of deformation, apart from the decrease in height of the specimen. Further deformation, however, led to the separation of the $\mathrm{Ti} / \mathrm{Al}$ layers following the kinking in the Ti-6Al-4V sheets (Fig. 5a), which corresponds to the rapid decline in hardening modulus, as shown in Fig. 2b. Comparing the height contour on the side surface before and after deformation (insets in Fig. 5a), strain localization was presumed to take place primarily in the region where kinking occurred. Quantitative statistical analysis of the strain evolution tracked in areas I and II, as pointed in Fig. 5a, confirmed that strain 

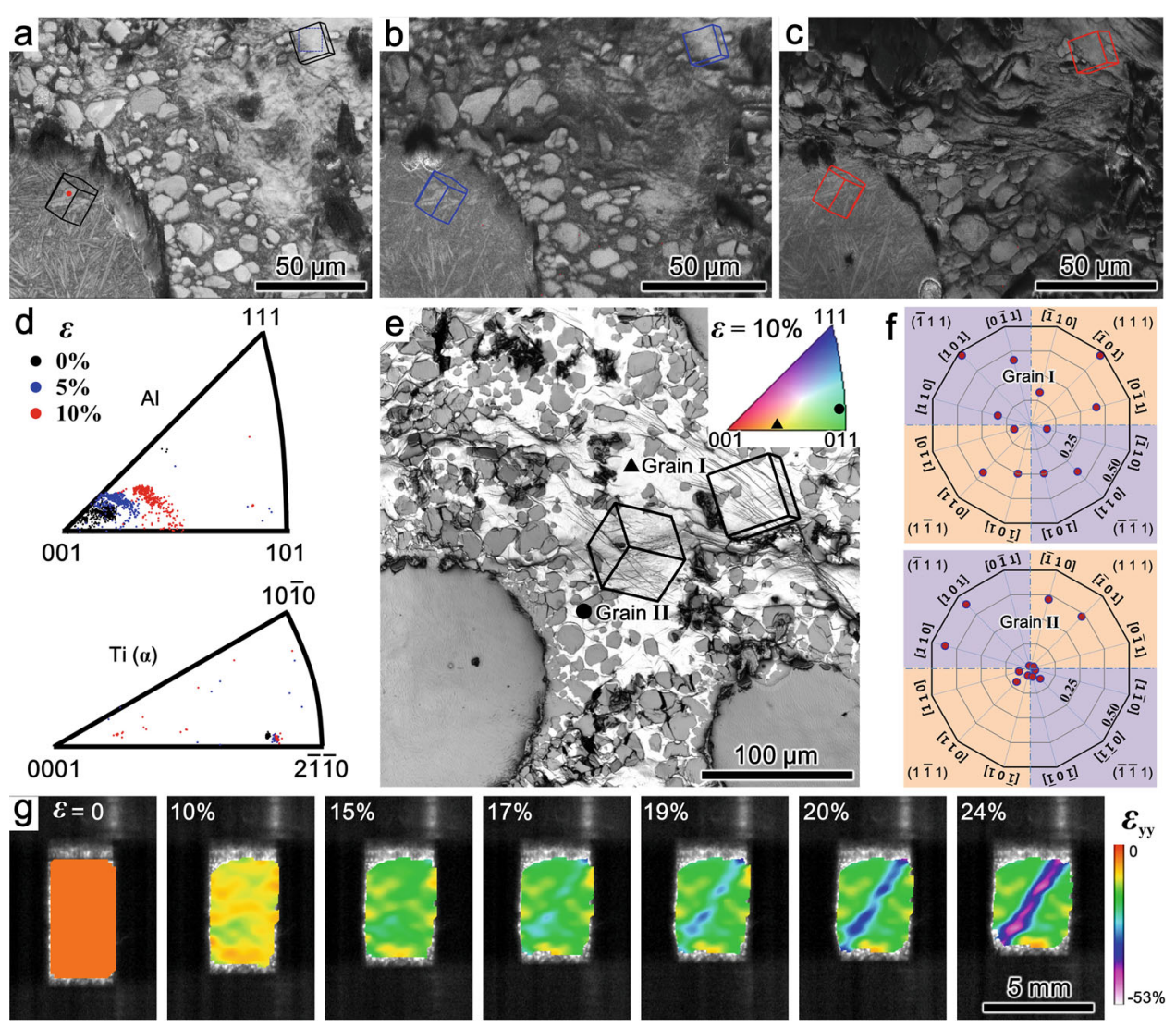

Fig. 3 Deformation behavior and strain localization in a ball-reinforced AMC. a-c Image quality (IQ) information obtained by quasi in situ EBSD characterization at a compressive strain $\varepsilon$ of $\mathbf{a} 0 \%, \mathbf{b} 5 \%$, and $\mathbf{c} 10 \%$. d Crystal orientation data displayed in the inverse pole figure (IPF) of the Al matrix (blue box in ' $a$ ') and Ti reinforcement (red point in ' $a$ '), indicating a clear grain rotation in the Al matrix during compression. e CLSM image showing damage features on the surface. $\mathbf{f}$ Schmid factor in various slipping systems during compression for grains I and II shown in 'e'. $\mathbf{g}$ Deformation and fracture feature images using the in situ DIC technique on a larger scale.

localization occurred even at the very start of the compression loading (Fig. 5b), which served to limit the plasticity of the whole sample (Fig. 2a, b). Microscopically, microcracks were observed to initiate in the $\mathrm{Al}_{3} \mathrm{Ti}$, or at the $\mathrm{Ti} / \mathrm{Al}_{3} \mathrm{Ti}$ interfaces, at a small strain (less than $2.7 \%$ ) before coalescing and propagating rapidly along the $\mathrm{Ti} /$ $\mathrm{Al}_{3} \mathrm{Ti}$ interfaces, driven by the kinking of the $\mathrm{Ti}$ layer (Fig. $5 \mathrm{c}-\mathrm{f}$ ).

In situ observation by optical microscopy (OM) enables an intuitive understanding of various fracture behaviors for reinforced AMCs on a macroscopic level (videos in Supporting Information). For the pure Al-Si alloy, multiple shear bands operated during compression. As a comparison, only one macroscopic shear band was observed until fracture in the ball-reinforced AMC due to the strain concentration and sacrifice of toughness. The rod-reinforced AMC failed through shearing as a whole, accompanied by some local separation along the vertical direction. For the plate-reinforced AMC, penetrated separation occurred before further deformation, causing failure. The fracture modes obtained from OM observations are summarized in Supplementary Fig. 5.

Figure 6 presents a series of transmission electron microscopy (TEM) images demonstrating the different microdamage mechanisms in the three AMCs after compression. In the ball-reinforced AMC, plastic deformation was confined to the $\mathrm{Al}$ matrix in the form of dislocation slip, principally on the primary slip plane (Fig. 6a). However, few such slip traces are clearly observed in the $\mathrm{Al}_{3} \mathrm{Ti}$ and $\mathrm{Ti}-6 \mathrm{Al}-4 \mathrm{~V}$ reinforcement, except for some dislocation pile-ups in the aluminum at the $\mathrm{Al} / \mathrm{Al}_{3} \mathrm{Ti}$ boundaries (Fig. 6b, c), which originated from Frank-Read sources within the grains and/or boundary ledges at interfaces. In the rod-reinforced AMC, veins and multiple slip bands dominated the dislocation configurations in the matrix (Fig. 6d, e) due to the complex straining conditions caused by normal stress from external loading combined with shear stress from neighboring Ti rods. Additionally, slip and twinning (the major deformation mode of $\mathrm{Al}_{3} \mathrm{Ti}$ as pointed out by Yamaguchi 

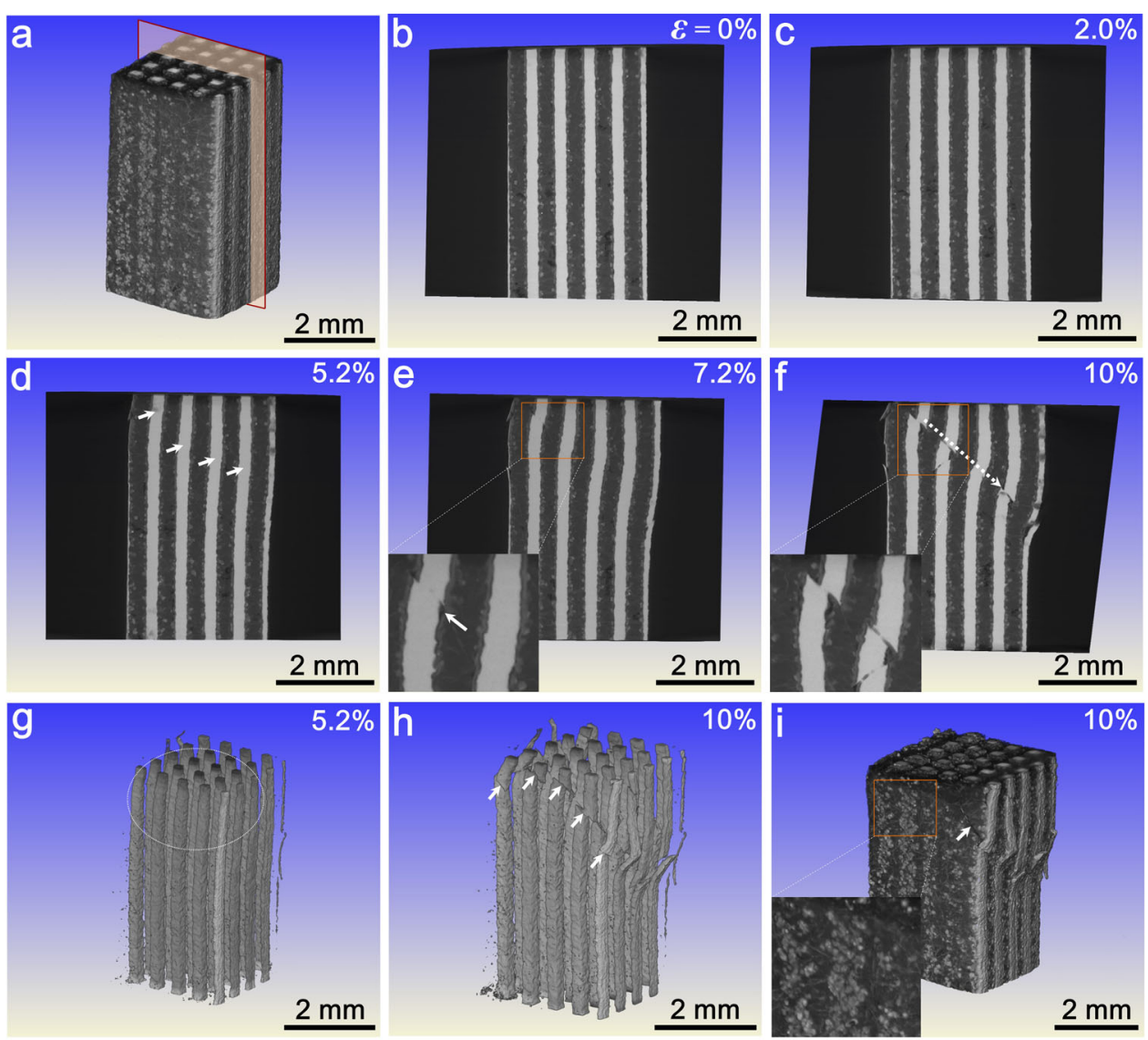

Fig. 4 3-D visualized damage morphology at various strains during the in situ compression test of a rod-reinforced AMC. a Illustration of position for tracking. b-f Damage features at 'a' observed from a cross-sectional view at various strains: b 0\%, c 2.0\%, d 5.2\%, e 7.2\%, and f $10 \%$, showing a failure mode of kinking $\rightarrow$ shearing $\rightarrow$ fracture. $\mathbf{g}$, $\mathbf{h}$ 3-D perspective displaying the deformation feature in Ti-6Al-4V rods, indicating a macroscopic shearing across the whole sample. i Surface damage feature after deformation, with the same observation site as that in ' $h$ '.

et $\mathrm{al}^{27}$ ) were observed in the $\mathrm{Ti}-6 \mathrm{Al}-4 \mathrm{~V}$ and $\mathrm{Al}_{3} \mathrm{Ti}$ phases, as shown in Fig. 6f, g, suggesting that both the reinforcement and the precipitate participate in the strengthening and toughening of the AMC. In contrast, only minimal dislocation activity, from slip and resulting pile-ups, was evident in the $\mathrm{Al}$ and $\mathrm{Ti}$ layers of the platereinforced AMC (Fig. 6h, i) due to their limited ductility.

\section{Discussion}

The ball-ball reinforcement displayed a low strengthening effect on the matrix, which is similar to most particle reinforcements in AMCs (Fig. 2b). The main restriction in strengthening may come from the strain localization, as mentioned above. A viable approach to diminish strain localization in the matrix is to reduce the particle size. However, decreasing the size or increasing the number of added reinforcement particles is invariably concomitant with an increase in porosity, especially for aluminum alloys with poor wettability ${ }^{28-30}$. In addition, the large discrepancy in hardness (or strength) between reinforcement and matrix further compromises the strengthening induced by the particles ${ }^{2}$. Compared to the ball-reinforced composites, both the rod- and plate-reinforced AMCs show excellent strength, although layer dissection occurred in the plate-reinforced AMCs during the initial stages of plastic deformation due to the brittle nature of the $\mathrm{Al}_{3} \mathrm{Ti}$ phase, which limited further plasticity and resultant strain hardening. The specific macro- and microscale strengthening mechanisms involved in these continuous metal-reinforced composites are summarized in Supplementary Fig. 6.

At the macroscopic level, the hardening but crisp constituents, Ti-6Al-4V and $\mathrm{Al}_{3} \mathrm{Ti}$, take full part in strengthening by building continuous bearing structures in the composite but also exhibit some plastic deformation ability with the help of the ductile $\mathrm{Al}$ matrix, considering that kinking and plastic shearing (without connected macrocracks) occur during compression (Fig. 4e, f). From the rule of mixtures (ROM), the average 


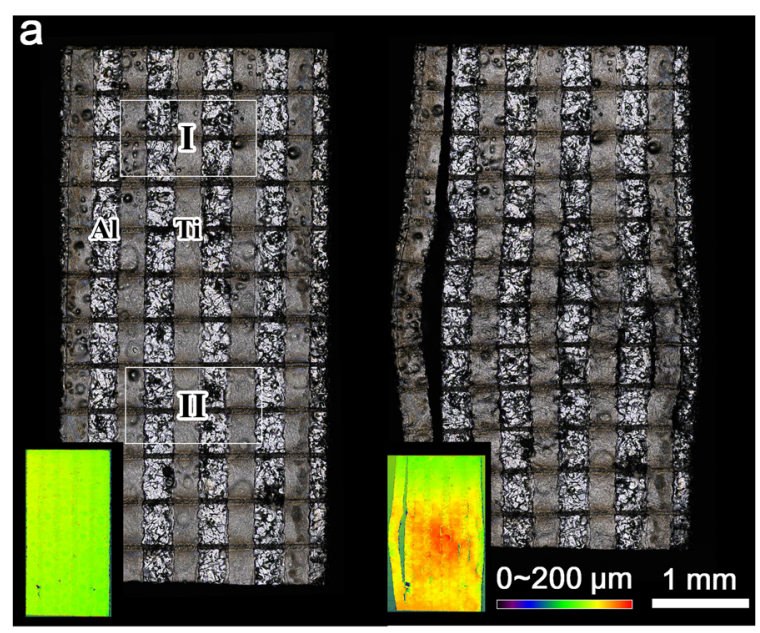

\section{b}
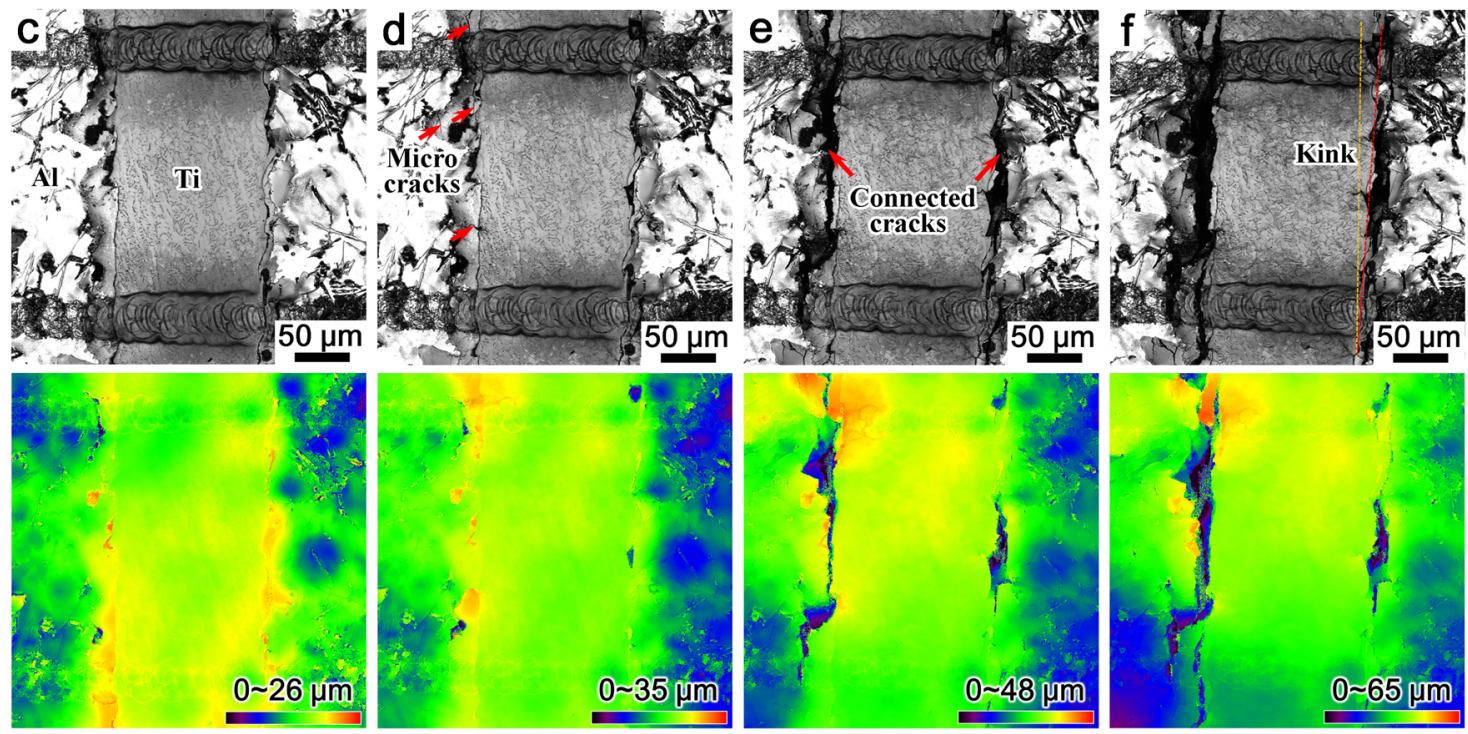

Fig. 5 Deformation and fracture behavior of a plate-reinforced AMC investigated by in situ CLSM (morphology and height) characterization. a Macroscopic deformation and damage features before and after failure. $\mathbf{b}$ Analysis of local strain: tracking the local strain evolution in areas I and II vs. global average strain. c-f Microscopic deformation and damage mechanisms at different global strains: c 0\%; d 2.7\%, crack initiating at the $\mathrm{Al}_{3} \mathrm{Ti}$ or the Ti/Al 3 Ti interface; e 4.9\%, microcracks connecting; $\mathbf{f} 6.3 \%$, macrocrack rapidly growing.

flow stress $\sigma$ of the entire AMC, in its simplest form, can be expressed as

$$
\sigma=\sigma_{1} \cdot f_{1}+\sigma_{2} \cdot f_{2}+\cdots+\sigma_{n} \cdot f_{n}
$$

where $\sigma_{1}, \sigma_{2}, \sigma_{n}$ and $f_{1}, f_{2}, f_{n}$ are the flow stress and volume fraction of materials 1,2 , up to $n$, respectively.

Table 1 shows the calculated results compared with the measured values for the three AMCs. Specifically, the measured yield strengths of the rod- or plate-reinforced AMCs are much higher than the sum of the strength of individual $\mathrm{Al}, \mathrm{Ti}$, and $\mathrm{Al}_{3} \mathrm{Ti}$ units, as calculated using ROM: the actual strength of the rod-reinforced AMC is $402 \mathrm{MPa}$, compared to a calculated ROM strength of $315 \mathrm{MPa}$, whereas the actual strength of the plate- reinforced AMC was $617 \mathrm{MPa}$ compared to a ROM value of $545 \mathrm{MPa}$. The ball-reinforced AMC exhibits a measured yield strength of $170 \mathrm{MPa}$, which is much lower than the ROM calculated value of $447 \mathrm{MPa}$. The overvalued strength of ball-reinforced AMC is supposed to result from the strain localization as mentioned above, while the difference between the theoretical prediction by the ROM and the measured value for the rod- or platereinforced AMC indicates the existence of other strengthening mechanisms in addition to the ROM. Similarly, the strength of the heterogeneous materials much higher than the sum of the value of separate units was also found in steels and $\mathrm{Ti}^{16,31,32}$.

In fact, the macroscopic properties of materials (e.g., strength of composites) not only depend on the 

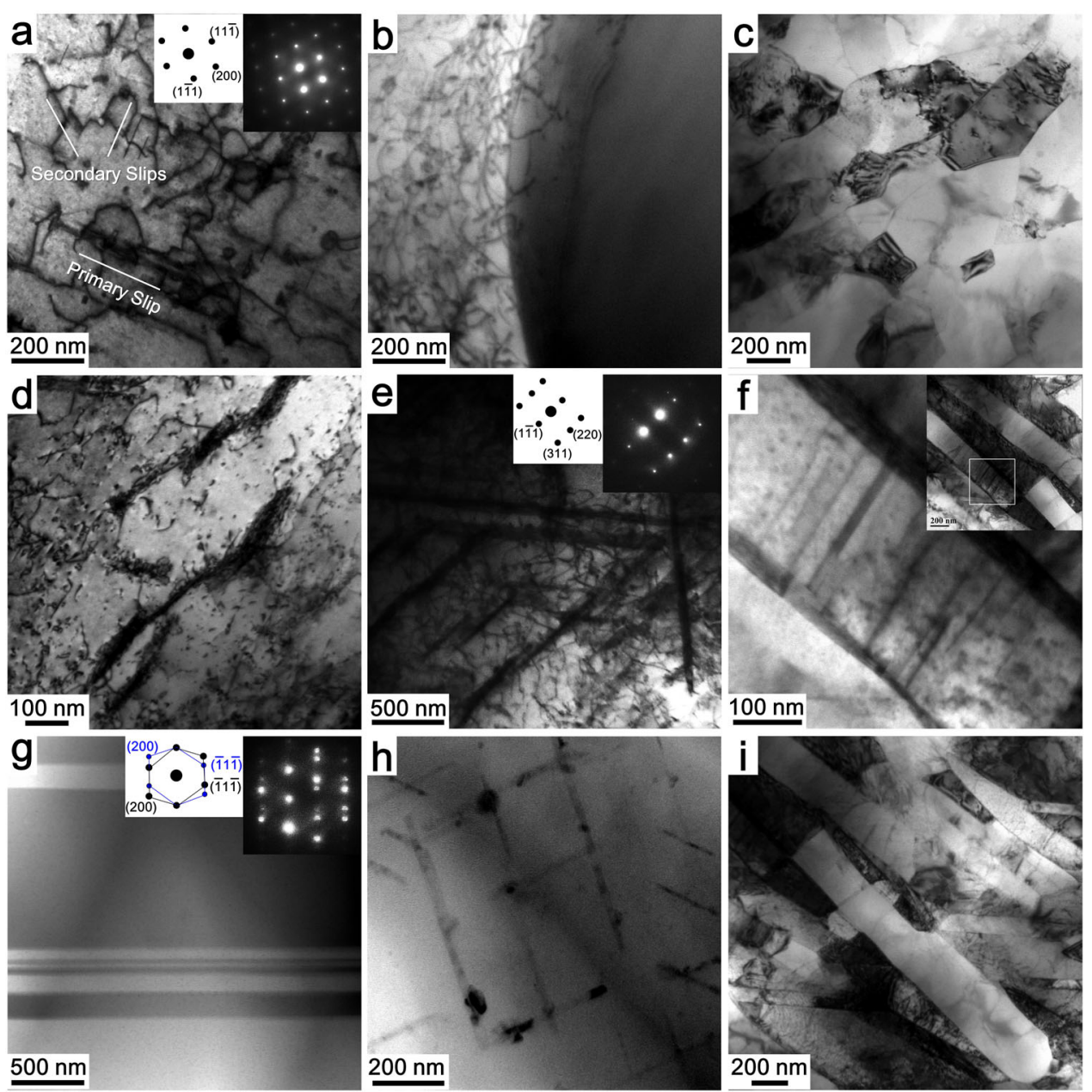

Fig. 6 Internal microdeformation and damage behavior of the three AMCs characterized by TEM. a-c 10\% compressed ball-reinforced AMC: a dislocation slip mainly on the primary slip plane in the Al matrix, $\mathbf{b}$ dislocation pile-up at an $\mathrm{Al}^{\mathrm{Al}} \mathrm{Al}_{3} \mathrm{Ti}$ interface, $\mathbf{c}$ clear Ti-6Al-4V grain. $\mathbf{d}-\mathbf{g} 10 \%$ compressed rod-reinforced AMC: $\mathbf{d}$ dislocation veins in the Al matrix, e multiple slip in the Al matrix, $\mathbf{f}$ dislocation slip in Ti-6Al-4V, $\mathbf{g}$ twinning in $\mathrm{Al}_{3} \mathrm{Ti} . \mathbf{h}$, i 5\% compressed plate-reinforced AMC: $\mathbf{h}$ limited slip in the Al matrix, i dislocation multiplication in Ti-6Al-4V. Note that damage microstructures after $5 \%$ strain instead of $10 \%$ are displayed in ' $h$ ' and ' $i$ ' for comparison because of the low plasticity in the plate-reinforced AMC. Nonhomogeneous deformation or even fracture may occur at strains exceeding $5 \%$.

Table 1 Comparison of yield strength measured and calculated for various reinforced Al alloys.

\begin{tabular}{lll}
\hline AMC & $\begin{array}{l}\text { Yield strength, MPa, } \\
\text { (measured) }\end{array}$ & $\begin{array}{l}\text { Yield strength, MPa, } \\
\text { (calculated by ROM) }\end{array}$ \\
\hline Ball-reinforced Al & 170 & 447 \\
Rod-reinforced Al & 402 & 315 \\
Plate-reinforced Al & 617 & 545 \\
\hline
\end{tabular}

Strength data of pure Al matrix and Ti-6Al-4V used for calculation came from compression tests, while the data of pure $\mathrm{Al}_{3} \mathrm{Ti}$ were obtained by the indentation method $^{37}$

compositions/crystal structures but are also influenced by the arrangement of functional units/ordered structures. Constructing ordered structures with functional units
(OSFUs) may lead to abnormal (exceptional) mechanical properties $^{33}$. It has been theoretically and experimentally proven that a composite with soft or compliant layers, one kind of OSFU material, has much higher fracture resistance and fracture strength than does the homogeneous brittle material, and the stiffness of the structure remains high $^{34,35}$. According to Kolednik et al. ${ }^{34}$, the crack driving force decreased greatly when the crack entered the soft layer. For the present rod-reinforced AMC, short cracks caused by shearing were found to be arrested in the $\mathrm{Al}$ matrix (Fig. 4e, f), which coincides with Kolednik's crack arrest model.

A nanosized silicide, most likely $\mathrm{Ti}_{5} \mathrm{Si}_{3}{ }^{21,22}$, precipitated within the $\mathrm{Al}_{3} \mathrm{Ti}$ during the casting process (Supplementary Fig. 2f), forming a secondary particle-reinforced structure in the present AMCs, which further contributes 
to strengthening. For the $\mathrm{Al}_{3} \mathrm{Ti} /$ silicide composite, the incompatibility in deformation between the plastically deforming matrix and the essentially rigid particles leads to the creation of intense strain gradients in the metallic matrix. According to Bourgeois ${ }^{36}$, the composite yield stress mainly depends on the volume fraction and modulus of the particle, as well as the shear modulus difference between the matrix and particle, in addition to the in situ matrix yield stress. In his theory, a large modulus difference between the matrix and reinforcement will significantly limit strengthening. Since $\mathrm{Al}_{3} \mathrm{Ti}$ is a rigid matrix with a hardness of $\sim 4.9 \mathrm{GPa}^{37}$, the difference between its shear modulus and that of the nanoscale silicide is likely to be relatively small compared to most particle-reinforced metal-matrix composites, which may provide for better strengthening. Moreover, hardness tests showed that the silicide-reinforced $\mathrm{Al}_{3} \mathrm{Ti}$ in the ballreinforced $\mathrm{AMC}$ was harder than pure $\mathrm{Al}_{3} \mathrm{Ti}$ (Supplementary Fig. 7).

Influenced by the diffusion behavior of $\mathrm{Ti}$ atoms, the $\mathrm{Al} /$ $\mathrm{Al}_{3} \mathrm{Ti}$ interfaces left by the precipitation of $\mathrm{Al}_{3} \mathrm{Ti}$ were very rough (Supplementary Fig. 2a-c). These rough interfaces improve the adhesive strength of $\mathrm{Al} / \mathrm{Al}_{3} \mathrm{Ti}$ effectively by interlocking the two phases, and more importantly, they help induce a macroscale strain gradient, which is essential to the generation of geometrically necessary dislocations (GNDs). In the simplest case, Al and $\mathrm{Al}_{3} \mathrm{Ti}$ were alternately distributed along the $\mathrm{Ti} / \mathrm{Al}_{3} \mathrm{Ti}$ interface with a regular concave-convex geometry (Supplementary Fig. 6). When the AMC is compressed, the actual stain at different positions is quite different. For example, the regions far from the interface show a strain close to the average value (bulk strain); near the interface, however, the strain in the $\mathrm{Al}$ matrix is much larger than the strain close to the $\mathrm{Al}_{3} \mathrm{Ti}$ due to their vastly different yield strength. As a result, a strain gradient forms during deformation. Then, the finite element method (FEM) was used to seek an intuitive understanding of the strain distribution in layered materials with rough interfaces (Supplementary Fig. 8). According to our previous work ${ }^{16}$, long-range GNDs, named meso-GNDs to distinguish them from the traditional GNDs proposed by Ashby, whose formation relates to the short-range strain discontinuity, would inevitably be introduced in the AMC by mesoscopic strain gradients, leading to additional strain hardening.

In addition to their roughness, the interfaces in the AMCs (including but not limited to $\mathrm{Ti} / \mathrm{Al}_{3} \mathrm{Ti}$ boundaries) commonly show microscopic ledges. These features, termed boundary ledge sources, are considered to be a source of dislocation arrays leading to the interfaceaffected zone (IAZ) ${ }^{38}$. IAZs are deemed to experimentally affect the Petch slope in the Hall-Petch relationship and, as such, influence the flow stress mechanistically by changing the microscopic strain gradient in terms of the dislocation density and their distribution. Though the theory and model ${ }^{38,39}$ for IAZ strengthening had been developed for a long time, convincing experimental evidence was only given very recently by Huang et al. ${ }^{13}$, who verified the existence of IAZs in copper-bronze laminates using in situ high-resolution strain mapping technology. These authors further estimated that the derived lengthscale (width) of the IAZ is on the order of a few micrometers. Such interfaces can generate both back-stress strengthening and work hardening, both of which result in higher strength. In short, compared with conventional homogeneous $\mathrm{Al}$ alloys, the $\mathrm{Ti}$ frame-reinforced AMC possess several multiple-scale strengthening features that are essential for producing extraordinary strength: (i) macroscopic strut reinforcement accompanied by nanoparticles (secondary reinforcement), (ii) mesoscopic strain-gradient strengthening, and (iii) microscopic interface ledge sources.

Our preliminary results also suggest that there is an optimal design of the frame structures in which the reinforcement can be oriented preferentially to resist the actual loading states and working conditions. To achieve this, 3-D printing technology can be applied to the current microcasting method for creating a custom frame with a complex structure. Typical examples include $\mathrm{Al}-\mathrm{Ti}$ composites with "brick wall" and lattice structures (Supplementary Fig. 9), which we have recently fabricated using SLM and EBM methods, respectively.

Our belief here is that there should be an optimum combination of microstructures in the $\mathrm{Al}$ matrix, Ti reinforcement and $\mathrm{Al}_{3} \mathrm{Ti}$ precipitates that produces the best strengthening effect without compromising the ductility. For instance, all the currently described AMCs show higher strength without sacrificing ductility after heat treatment (Supplementary Fig. 10). It should also be noted here that the present ball reinforcements show a strengthening capacity in AMCs similar to that of traditional particle reinforcements, which essentially have their origin from the breaking of ball-ball connections during matrix deformation and thus largely weaken the strengthening effect due to the lack of macroscopic strut reinforcement. If the $\mathrm{Ti}-6 \mathrm{Al}-4 \mathrm{~V}$ balls can be fixed to each other, which can be easily realized by further formation of $\mathrm{Al}_{3} \mathrm{Ti}$ on a $\mathrm{Ti}-6 \mathrm{Al}-4 \mathrm{~V}$ ball through diffusion of $\mathrm{Ti}$ atoms above the $\mathrm{Al}$ liquefaction temperature of $\mathrm{Al}$, their strengthening effect is likely to be greatly improved, although further studies are needed to verify this hypothesis.

In conclusion, the current work introduces a new technology, microcasting, to produce AMCs with complex structures and extraordinary strength. Considering the flexibility of the strut shape, microcasting provides unique advantages for reinforcement in the demand position and direction for casting alloys. Because the 
processing technique can impart multiple reinforcements, the strengths of the resulting $\mathrm{Al}$ composites can reach values as much as 4-6 times higher than that of the Al-Si alloy matrix. Specifically, the current rod-reinforced AMC exhibits the highest yield strength of all cast $\mathrm{Al}-\mathrm{Si}$ alloys, and the plate-reinforced AMC displays the highest strength of all cast commercial aluminum alloys. Moreover, our microcasting method to process AMCs is both cost-effective and readily scalable, and it is therefore expected to be conducive to industrial production.

\section{Acknowledgements}

This work was financially supported by the National Natural Science Foundation of China (NSFC) under grant nos. 51501198, 51771208 and 51801216, Open Foundation of Key Laboratory of Fundamental Science for National Defence of Aeronautical Digital Manufacturing Process under grant no. SHSYS201803, Natural Science Foundation of Liaoning Province under grant no. 20180540142, and the IMR SYNL-T.S. Kê Research Fellowship.

\section{Author details}

${ }^{1}$ Laboratory of Fatigue and Fracture for Materials, Institute of Metal Research, Chinese Academy of Sciences, Shenyang 110016, P. R. China. ${ }^{2}$ Key Laboratory of Fundamental Science for National Defense of Aeronautical Digital Manufacturing Process, Shenyang Aerospace University, Shenyang 110136 , P. R. China. ${ }^{3}$ Department of Materials Science and Engineering, University of California Berkeley, Berkeley, CA 94720, USA

\section{Author contributions}

Z.F.Z. and R.O.R. conceived the initial research idea. S.Z. and C.W.S. developed the microcasting technique and designed the experiments. S.Z. prepared the AMC samples. C.W.S. and X.G.W. carried out the mechanical and DIC experiments. C.W.S. performed all the microstructural characterizations. Z.F.Z. and C.W.S. proposed the models and mechanisms. C.W.S., S.Z., R.O.R., and Z.F.Z. analyzed the data and wrote the paper. All authors contributed to the scientific discussions.

\section{Data availability}

The data that support the findings of this study are available from the corresponding author, Prof. Zhefeng Zhang, at zhfzhang@imr.ac.cn, upon reasonable request.

\section{Conflict of interest}

The authors declare that they have no conflict of interest.

\section{Publisher's note}

Springer Nature remains neutral with regard to jurisdictional claims in published maps and institutional affiliations.

Supplementary information is available for this paper at https://doi.org/ 10.1038/s41427-019-0174-2.

Received: 20 June 2019 Revised: 3 October 2019 Accepted: 7 October 2019. Published online: 29 November 2019

\section{References}

1. Surappa, M. K. Aluminium matrix composites: challenges and opportunities. Sadhana 28, 319-334 (2003).

2. Kouzeli, M. \& Mortensen, A. Size dependent strengthening in particle reinforced aluminium. Acta Mater. 50, 39-51 (2002).

3. Wang, A. \& Rack, H. J. Transition wear behavior of SiC-particulate- and SiCwhisker-reinforced 7091 Al metal matrix composites. Mater. Sci. Eng. A 147, 211-224 (1991)

4. He, C. et al. An approach to obtaining homogeneously dispersed carbon nanotubes in Al powders for preparing reinforced Al-matrix composites. Adv. Mater. 19, 1128-1132 (2007).
5. Wang, J. et al. Reinforcement with graphene nanosheets in aluminum matrix composites. Scr. Mater. 66, 594-597 (2012).

6. Rohatgi, P. Cast aluminum-matrix composites for automotive applications. JOM 43, 10-15 (1991).

7. Rawal, S. P. Metal-matrix composites for space applications. JOM 53, 14-17 (2001).

8. Pai, B. C., Ramani, G., Pillai, R. M. \& Satyanarayana, K. G. Role of magnesium in cast aluminium alloy matrix composites. J. Mater. Sci. 30, 1903-1911 (1995).

9. Suresh, S. Graded materials for resistance to contact deformation and damage. Science 292, 2447-2451 (2001).

10. Wei, Y. J. et al. Evading the strength-ductility trade-off dilemma in steel through gradient hierarchical nanotwins. Nat. Commun. 5, 3580 (2014).

11. Shao, C. W. et al. Improvement of low-cycle fatigue resistance in TWIP steel by regulating the grain size and distribution. Acta Mater. 134, 128-142 (2017).

12. Huang, M. et al. Role of layered structure in ductility improvement of layered Ti-Al metal composite. Acta Mater. 153, 235-249 (2018).

13. Huang, C. X. et al. Interface affected zone for optimal strength and ductility in heterogeneous laminate. Mater. Today 21, 713-719 (2018).

14. Ojima, M. et al. Stress partitioning behavior of multilayered steels during tensile deformation measured by in situ neutron diffraction. Scr. Mater. $\mathbf{6 6}$ 139-142 (2012).

15. Lhuissier, P., Inoue, J. \& Koseki, T. Strain field in a brittle/ductile multilayered steel composite. Scr. Mater. 64, 970-973 (2011).

16. Shao, C. W. et al. Simultaneous improvement of strength and plasticity: Additional work-hardening from gradient microstructure. Acta Mater. 145, 413-428 (2018).

17. Yang, M. X., Pan, Y., Yuan, F. P., Zhu, Y. T. \& Wu, X. L. Back stress strengthening and strain hardening in gradient structure. Mater. Res. Lett. 4, 145-151 (2016).

18. Zhao, S. et al. Compressive and fatigue behavior of functionally graded Ti-6Al-4V meshes fabricated by electron beam melting. Acta Mater. 150, 1-15 (2018).

19. Harach, D. J. \& Vecchio, K. S. Microstructure evolution in metal-intermetallic laminate (MIL) composites synthesized by reactive foil sintering in air. Metall. Mater. Trans. A 32, 1493-1505 (2001).

20. Sujata, M., Bhargava, S. \& Sangal, S. Microstructural features of $\mathrm{TiAl}_{3}$ base compounds formed by reaction synthesis. Isij Int. 36, 255-262 (1996).

21. Liu, K. W., Zhang, J. S., Wang, J. G. \& Chen, G. L. Formation of intermetallic nanocomposites in the Ti-Al-Si system by mechanical alloying and subsequent heat treatment. J. Mater. Res. 13, 1198-1203 (2011).

22. Manna, I., Nandi, P., Bandyopadhyay, B., Ghoshray, K. \& Ghoshray, A. Microstructural and nuclear magnetic resonance studies of solid-state amorphization in Al-Ti-Si composites prepared by mechanical alloying. Acta Mater. $\mathbf{5 2}$ 4133-4142 (2004).

23. Watanabe, Y., Sequeira, P. D., Sato, H., Inamura, T. \& Hosoda, H. Aluminum matrix texture in Al-Al3Ti functionally graded materials analyzed by electron back-scattering diffraction. Jpn. J. Appl. Phys. 55, 01 AG03 (2015).

24. Zolotorevsky, V. S., Belov, N. A. \& Glazoff, M. V. Casting Aluminum Alloys. Vol. 12 (Elsevier Amsterdam, 2007)

25. Zhang, Z. F., He, G., Eckert, J. \& Schultz, L. Fracture mechanisms in bulk metallic glassy materials. Phys. Rev. Lett. 91, 045505 (2003).

26. Qu, R. T., Liu, Z. Q., Wang, G. \& Zhang, Z. F. Progressive shear band propagation in metallic glasses under compression. Acta Mater. 91, 19-33 (2015).

27. Yamaguchi, M., Umakoshi, Y. \& Yamane, T. Plastic deformation of the intermetallic compound Al3Ti. Philos. Mag. A 55, 301-315 (1987).

28. Sajjadi, S. A., Ezatpour, H. R. \& Torabi Parizi, M. Comparison of microstructure and mechanical properties of $\mathrm{A} 356$ aluminum alloy/ $/ \mathrm{Al}_{2} \mathrm{O}_{3}$ composites fabricated by stir and compo-casting processes. Mater. Des. 34, 106-111 (2012).

29. Hashim, J., Looney, L. \& Hashmi, M. S. J. The enhancement of wettability of SiC particles in cast aluminium matrix composites. J. Mater. Process. Technol. 119 329-335 (2001)

30. Tekmen, C., Ozdemir, I., Cocen, U. \& Onel, K. The mechanical response of $\mathrm{Al}-\mathrm{Si}-\mathrm{Mg} / \mathrm{SiC}$ composite: influence of porosity. Mater. Sci. Eng. A $\mathbf{3 6 0}$, 365-371 (2003).

31. $\mathrm{Wu}, \mathrm{X}$. L. et al. Synergetic strengthening by gradient structure. Mater. Res. Lett. 2, 185-191 (2014).

32. $\mathrm{Wu}, \mathrm{X}$. L. et al. Heterogeneous lamella structure unites ultrafine-grain strength with coarse-grain ductility. Proc. Natl Acad. Sci. USA 112, 14501-14505 (2015).

33. Chen, K. \& Li, L. Ordered structures with functional units as a paradigm of material design. Adv. Mater. 31, 1901115 (2019). 
34. Kolednik, O., Predan, J., Fischer, F. D. \& Fratzl, P. Bioinspired design criteria for damage-resistant materials with periodically varying microstructure. Adv. Funct. Mater. 21, 3634-3641 (2011).

35. Miserez, A. et al. Effects of laminate architecture on fracture resistance of sponge biosilica: Lessons from nature. Adv. Funct. Mater. 18, 1241-1248 (2008).

36. Bourgeois N. Behavior and damage of an Al/SiCp metal matrix composite: characterization and micromechanical modelling. PhD thesis (Ecole Centrale de Paris, 1994).

37. Milman, Y. V. et al. Mechanical behaviour of Al3Ti intermetallic and L12 phases on its basis. Intermetallics 9, 839-845 (2001).

38. Murr, L. E. Dislocation ledge sources: dispelling the myth of Frank-Read source importance. Metall. Mater. Trans. A 47, 5811-5826 (2016).

39. Li, J. C. M. High-angle tilt boundary-a dislocation core model. J. Appl. Phys. 32, 525-541 (1961).

40. Zhang, W. Y., Du, Y. H. \& Zhang, P. Vortex-free stir casting of Al-1.5wt\% Si-SiC composite. J. Alloy. Compd. 787, 206-215 (2019).

41. Cöcen, Ü. \& Önel, K. Ductility and strength of extruded $\mathrm{SiC}_{\mathrm{p}}$ /aluminium-alloy composites. Compos. Sci. Technol. 62, 275-282 (2002).

42. Boopathi, M. M., Arulshri, K. \& lyandurai, N. Evaluation of mechanical properties of aluminium alloy 2024 reinforced with silicon carbide and fly ash hybrid metal matrix composites. Am. J. Appl. Sci. 10, 219 (2013).
43. Ashok Kumar, B. \& Murugan, N. Metallurgical and mechanical characterization of stir cast AA6061-T6-AIN composite. Mater. Des. 40, 52-58 (2012).

44. Raviraj, M. S., Sharanprabhu, C. M. \& Mohankumar, G. C. Experimental analysis on processing and properties of Al-TiC metal matrix composites. Procedia Mater. Sci. 5, 2032-2038 (2014).

45. Mohapatra, S., Chaubey, A. K. Mishra, D. K. \& Singh, S. K. Fabrication of Al-TiC composites by hot consolidation technique: its microstructure and mechanical properties. J. Mater. Res. Technol. 5, 117-122 (2016).

46. Noguchi, T. et al. Carbon nanotube/aluminium composites with uniform dispersion. Mater. Trans. 45, 602-604 (2004).

47. Kala, H., Mer, K. K. S. \& Kumar, S. A review on mechanical and tribological behaviors of stir cast aluminum matrix composites. Procedia Mater. Sci. 6 , 1951-1960 (2014)

48. Zhao, D. G., Liu, X. F., Pan, Y. C., Liu, Y. X. \& Bian, X. F. Microstructure and mechanical behavior of AlSiCuMgNi piston alloys reinforced with $\mathrm{TiB}_{2}$ particles. J. Mater. Sci. 41, 4227-4232 (2006).

49. Lü, L., Lai, M. O., Su, Y., Teo, H. L. \& Feng, C. F. In situ TiB 2 reinforced Al alloy composites. Scr. Mater. 45, 1017-1023 (2001).

50. Chen, Z., Kang, H., Zhao, Y., Zheng, Y. \& Wang, T. The role of $\mathrm{TiB}_{2}$ in strengthening $\mathrm{TiB}_{2}$ reinforced aluminium casting composites. IOP Conf. Ser. Mater. Sci. Eng. 117, 012039 (2016). 